\title{
Metamorphoses of Lyme disease spirochetes: phenomenon of Borrelia persisters
}

\author{
Natalie Rudenko ${ }^{1 *+}$, Maryna Golovchenko ${ }^{1 \dagger}$, Katerina Kybicova $^{2}$ and Marie Vancova ${ }^{1}$
}

\begin{abstract}
The survival of spirochetes from the Borrelia burgdorferi (sensu lato) complex in a hostile environment is achieved by the regulation of differential gene expression in response to changes in temperature, salts, nutrient content, acidity fluctuation, multiple host or vector dependent factors, and leads to the formation of dormant subpopulations of cells. From the other side, alterations in the level of gene expression in response to antibiotic pressure leads to the establishment of a persisters subpopulation. Both subpopulations represent the cells in different physiological states. "Dormancy" and "persistence" do share some similarities, e.g. both represent cells with low metabolic activity that can exist for extended periods without replication, both constitute populations with different gene expression profiles and both differ significantly from replicating forms of spirochetes. Persisters are elusive, present in low numbers, morphologically heterogeneous, multi-drug-tolerant cells that can change with the environment. The definition of "persisters" substituted the originally-used term "survivors", referring to the small bacterial population of Staphylococcus that survived killing by penicillin. The phenomenon of persisters is present in almost all bacterial species; however, the reasons why Borrelia persisters form are poorly understood. Persisters can adopt varying sizes and shapes, changing from well-known forms to altered morphologies. They are capable of forming round bodies, L-form bacteria, microcolonies or biofilms-like aggregates, which remarkably change the response of Borrelia to hostile environments. Persisters remain viable despite aggressive antibiotic challenge and are able to reversibly convert into motile forms in a favorable growth environment. Persisters are present in significant numbers in biofilms, which has led to the explanation of biofilm tolerance to antibiotics. Considering that biofilms are associated with numerous chronic diseases through their resilient presence in the human body, it is not surprising that interest in persisting cells has consequently accelerated. Certain diseases caused by pathogenic bacteria (e.g. tuberculosis, syphilis or leprosy) are commonly chronic in nature and often recur despite antibiotic treatment. Three decades of basic and clinical research have not yet provided a definite answer to the question: is there a connection between persisting spirochetes and recurrence of Lyme disease in patients?
\end{abstract}

Keywords: Borrelia burgdorferi, Persisters, Dormant forms, Round bodies, Biofilm, Lyme disease, Persistent infection, Antibiotic treatment

\footnotetext{
*Correspondence: natasha@paru.cas.cz

${ }^{\dagger}$ Natalie Rudenko and Maryna Golovchenko contributed equally to this

work

${ }^{1}$ Biology Centre CAS, Institute of Parasitology, Branisovska 31,

37005 Ceske Budejovice, Czech Republic

Full list of author information is available at the end of the article
} 


\section{Background}

Lyme disease (LD) is a multisystem disorder caused by certain species of spirochetes from the Borrelia burgdorferi (sensu lato) complex. Since all Borrelia species are host-propagated bacteria that move between a vertebrate host and tick vector, the spirochetes have developed strategies to sense and survive in these diverse environments [1-4]. Survival is achieved by altering the level of gene expression in response to changes in temperature, $\mathrm{pH}$, salts, nutrient content, multiple host and vector dependent factors [5-10]. Nutrients, especially carbon sources, and/or their metabolic by-products seem to provide regulatory and chemotactic signals that guide the spirochete as it moves between hosts and vectors. The spirochetes that are exposed to antibiotic treatment are able to survive by regulation of the differential expression of genes involved in spirochete pathogenicity and the mechanism of persister formation [11-13]. However, the change in gene expression level is not the only route to spirochete survival. Signals that Borrelia receives from hostile environments evoke morphological alterations that keep the pathogen alive and induce the production of atypical forms or persisters that are refractory to elimination. The formation of persisters in vitro and in vivo is a reversible process that establishes the basis for disease recurrence when the hostile pressure drops [8, 14-18].

The successful persistence of spirochetes within the host depends on evading the host's immune system, e.g. hiding of spirochetes within the extracellular matrix rather than using the host tissues for reproduction or growth [19-21]. Multiple experimental animal studies have shown that Borrelia frequently establishes persistent infection in diverse vertebrate hosts including laboratory mice of $\mathrm{C} 3 \mathrm{H} / \mathrm{HeJ}, \mathrm{BALB} / \mathrm{cByJ}, \mathrm{C} 3 \mathrm{H} / \mathrm{HeN}$ CrlBR, C3H-scid, SJL or B6 Myd88-/- genotypes [17, 22-28], white-footed mice Peromyscus leucopus [29, 30], rats [31], hamsters [32, 33], guinea pigs [34, 35], gerbils [36], dogs [37-39], horses [40-42] and non-human primates [43-49]. Clinical evidence extends this paradigm to humans including those who underwent antibiotics treatment [50-85].

The hosts' immune responses to LD spirochete, pharmacokinetic and pharmacodynamic parameters of antibiotic treatment in animals and humans, infectious dose and the route of infection are not the same [86]. It is clear that results obtained on laboratory animal models might not be simply applied to explain the phenomenon of persisters in human LD. However, the extended examples of diverse strategies used by LD spirochete in its competition for survival, i.e. active immune suppression, induction of immune tolerance, phase and antigenic variation, intracellular seclusion, or incursion into immune privileged sites, provide strong evidence of the capability of spirochetes to persist in vertebrate hosts $[4,87]$.

\section{Facing antibiotic challenge}

Frequent failures to respond to antibiotic treatment have recently become a serious public health problem. The common explanation of such cases is the emergence of a superinfection as a result of the development of bacterial resistance. Bacteria are able to develop resistance to the majority of clinically used antibiotics and the extended emergence of multi-drug-resistant pathogens is secured by the wide use of antibiotics in daily life by the general population, in hospitals, in agriculture or farming. There is no doubt that resistance is the main culprit of antibiotic treatment failures; however, less obvious reasons must be taken into consideration as well. One of these reasons is a phenomenon known as bacterial persistence, the case when bacteria survive the killing action of antibiotics by changing its physiological state.

Lyme disease is an infectious disease that can usually be successfully cured by antibiotic therapy at the very early stages of infection, targeting the replicative form of the spirochete [88-90]. Antibiotic treatment of microbial populations in general and B. burgdorferi (s.l.) in particular, results in biphasic killing [16, 18], eliminating the growing bacteria and inducing the appearance of a subpopulation of multi-drug tolerant cells, persisters [91, 92]. When the antibiotic concentration exceeds a certain threshold, only persister cells survive [18]. Persisters are tolerant to antibiotics without having acquired resistance to them through genetic modification [93]. Persistence is a non-inheritable feature. This discriminates persistent cells from resistant mutants, which exhibit stable, inheritable drug insensitivity [94]. A decrease of antibiotic pressure leads to the rise of a cell population that is as susceptible to antibiotics as the original population. A raised cell population called "reverters" constitutes a very small proportion of persisters that could revert to replicating forms and cause relapse or chronic infection $[18,95]$.

Persistence, as the response to hostile challenge, is an essential strategy for the complex life-cycle of Borrelia in both vector ticks and reservoir hosts, and likely applies to regular vertebrate hosts as well as to incidental ones such as humans. The ability of LD spirochetes to transform into persisters in response to antibiotic treatment explains the surprising resistance of chronic infection to therapy with antibiotics that are effective in the elimination of replicative Borrelia in vitro [18]. 


\section{Different stressors: diverse pleomorphic forms}

In addition to the well-known flat-wave forms of B. burgdorferi (s.l.) spirochetes, the existence of non-motile atypical morphologies such as looped or ring shaped forms, blebs, round bodies (RB) and cell wall deficient forms, spirochete colonies or biofilm aggregates have been described [14, 95-105]. The generalized definition of "round bodies" also includes coccoid-, globular- or spherical bodies, granules, cysts, sphaeroplasts or vesicles; all of these are viable reproductive propagules whose formation is induced by hostile environmental conditions [106]. The morphological changes of motile B. burgdorferi (s.l.) spirochetes are observed in vitro in response to incubation with water or serum starvation, a change of media composition, gas composition, oxidative stress, $\mathrm{pH}$ or temperature fluctuation, media acidityalkalinity fluctuation, concentrations of salts, sugars or other organic compounds, or as a response to antibiotic treatment [7, 14, 100, 104-108]. The formation of RBs in culture is induced by aging, and the appearance of RBs correlates with the disappearance of motile spirochetes [106, 108]. Mistakenly, transformation of the motile form into a RB was considered as a decrease of pathogen viability. However, even though RBs are less motile than spirochetes in a log phase culture, they are able to twitch or move laterally and revert to the active growing reproductive wave-form spirochetes under the favorable conditions [7, 14, 15, 100, 101, 103-107, 109]. In addition to spirochetes from the B. burgdorferi (s.l.) complex, reversible pleomorphism has been confirmed in other species from the genus Spirochaeta [110-113] and strengthened by the discovery of Spirochaeta coccoides, a new member of the genus Spirochaeta that grows and reproduces in RB forms only [111]. The formation of RBs in vitro as a response to exposure to the $\beta$-lactam antibiotics commonly recommended for LD treatment was described more than 20 years ago [105]. Persistence of Borrelia in hosts after antibiotic treatment has been already confirmed [17, 32, 48, 49, 85]. Atypical cystic forms were also observed in the cerebral cortex of a patient with chronic Lyme neuroborreliosis [101]. Borrelia aggregates or biofilms have been detected in skin biopsies isolated from patients who developed rare but typical lymphocytomas after a tick bite $[114,115]$. Biofilms, consisting of bacteria embedded in a self-produced polysaccharide matrix, are known to cause chronic infections due to their tolerance to antibiotic treatment and resistance to host serum complement $[94,96,106,114,116]$.

\section{Different susceptibility of persisters to antibiotics}

Persisters are highly heterogeneous [8, 96-101, 104, $106,114]$. Stress persisters differ from antibiotic persisters of the same Borrelia species due to the origin of condition that triggered their transformation. In vitro persisters differ from in vivo persisters due to the difference in environment in which the spirochetes reside [95]. It is still unknown if the same morphological forms, for example RBs formed in response to antibiotic exposure, are the same as RBs that are present in excess in stationary growth culture [109]. Recent studies confirmed that the susceptibility of heterogeneous persisters to a diverse spectrum of antibiotics is also different $[102,117]$. Results of the study of three morphological forms of Borrelia in vitro revealed that five antimicrobial drugs commonly used as monotherapy in LD cases (doxycycline, amoxicillin, tigecycline, metronidazole and tinidazole) showed different potential in eradicating spirochetes, round bodies and biofilm-like colonies [102]. While significant killing was shown by all five drugs in the case of replicating spirochetes (85-90\%) and round bodies (68-90\%), neither one of the studied drugs was able to reduce the spirochete colony formation more than $55 \%$. In the same study, viable spirochetes were detected in $70-85 \%$ of biofilm-like colonies [102]. Another study [117] revealed that tolerance to antibiotics is increased by different forms of spirochetes as culture ages, from log phase to stationary phase, from spirochete form to RB, micro-colonies or biofilms. The same study confirmed that the use of multiple drugs (triple combination) is much more effective in eradicating spirochete persisters. The complete eradication of biofilm-like spirochete micro-colonies in vitro was confirmed for a combination of daptomycin + doxycycline + cefoperazone, something that has not been achieved before with any single, dual or even triple drug combination [117]. Another option for successful eradication of Borrelia persisters in vitro is the pulse dosing of antibiotics [18]. While a combination of multiple antibiotics from different classes analyzed in the mentioned study did not improve the killing of persisters, four pulse doses of cetriaxone eradicated all live spirochetes in culture, including persisters [18].

The antibiotic treatment of LD is a real challenge, sometimes with unpredicted outcomes, and is another paradox in the LD portfolio. Although seemingly illogical, multiple frontline antibiotics used to cure early LD are triggering, at much lower concentrations than used in therapy, the transformation of the spiral form of Borrelia into varieties of persisting forms $[12,106]$. As a result, the Borrelia population becomes tolerant to the antibiotics that induced the morphological transformation. A good example of this paradox is doxycycline and amoxicillin, which at high concentrations are capable of eliminating 98\% of replicating Borrelia, but show poor activity against a stationary phase culture that is rich in persisting forms. Both drugs are ineffective against $\mathrm{RBs}$, the formation of which they induce in culture [12, 102, 105, 
$106,108]$. It is interesting to note that morphologically changed forms represent spirochete populations with different gene expression profiles, characteristic for the specific antibiotic, doxycycline or amoxicillin, used for in vitro culture treatment. It was shown that treatment of B. burgdorferi B31 culture for six days with $50 \mu \mathrm{g} / \mathrm{ml}$ of doxycycline or $50 \mu \mathrm{g} / \mathrm{ml}$ of amoxicillin resulted in differential expression of 675 genes in the doxycycline-tolerant population (340 downregulated and 335 upregulated) and 516 genes in the amoxicillin-tolerant population (174 downregulated and 342 upregulated) [12]. Binding to the $30 \mathrm{~S}$ ribosomal subunit, doxycycline obstructs the protein synthesis that causes the cell envelope defect. Amoxicillin inhibits the synthesis of bacterial cell walls that results in the death of bacteria. A comparison of the pathways of doxycycline- and amoxicillin-induced RBs shows that they share some common features that likely contribute to the enabling of spirochete survival under antibiotic pressure by downregulation of outer membrane lipoprotein gene expression. It is possible that one of the strategies spirochetes use to survive antibiotic treatment is the reduction of drug targets [12].

Amoxicillin-induced RBs have been used as an alternative model to stationary phase culture of $B$. burgdorferi in screening drugs active against persisters in vitro. Both models showed different susceptibilities to the same tested drugs. Because the structure of stationary phase culture is more complex, as it is enriched with RBs, micro-colonies and biofilm- like aggregates, its tolerance to tested antibiotics was shown to be higher in comparison to amoxicillin-induced round bodies [109].

\section{Genetic factors involved in persistence}

A genetically homogeneous population of spirochetes can dynamically alter gene expression in response to changing environmental conditions. When external stimuli on a bacterial subpopulation randomly trigger expression of genes that induce a state of dormancy, then a persister subpopulation can emerge. Persistence only occurs in a subpopulation of Borrelia cells that faces hostile pressure and is characterized by switching between two phenotypes, i.e. susceptible and persistent. Borrelia burgdorferi has been shown to persist when treated with tetracycline antibiotics [49]. Even though the mechanism of persistence for Borrelia has not yet been described, studies of bacterial persisters in fungi, parasites or viruses with a number of identified pathways and genes have shed light on the mechanism of persister formation and survival. The identified pathways in bacterial persisters could serve as potential targets for the development of new anti-persister drugs. These include, for example, toxin-antitoxin modules (hipBA, relBE, mazEF, tis $A B$, $m q s R, h h A, h o k A, \operatorname{csp} D$, pasT), stringent response (relA, $d k s A)$, DNA repair or protection (lexA, recA, recB, xerC, $x e r D, d p s)$, phosphate metabolism (phoU), alternative energy production ( $s u c B, u b i F, g l p D, p l s B, \operatorname{tgs} 1)$, anti-oxidative stress or macromolecule degradation (superoxide dismutase, catalase) or signaling pathways (comE/comC; tnaA, oxyR, flu, pspBC) (for review see [95]). As in vitro persisters differ from in vivo persisters, a drug that can kill all in vitro persisters is not guaranteed to do so in vivo. Nevertheless, the in vitro persisters may share some common features with in vivo persisters and in vitro persister models should still have significant value in persister studies as surrogates of in vivo persisters. Possible overlap between different persisters can be studied using single-cell techniques or RNA sequencing analysis to determine the expression pattern of genes that are differentially regulated by the pathogen as a survival strategy in response to hostile pressure.

\section{Biofilms}

In general, biofilm formation is an example of bacterial adaptation to a changing environment, occurring primarily for four reasons: (i) defense; (ii) colonization; (iii) community; and (iv) the default mode of bacterial growth [118]. In particular, biofilm formation is a stage of microbial development and a part of the mechanism of establishment of chronic bacterial infection [119-121]. More than 40 years have already passed from the first mention of tangled fibers of polysaccharides that extend from the cell surface and form "glycocalyx" around the individual cells or a colony of bacteria. The glycocalyx-mediated adhesion was described as a major determinant in the initiation and progression of the wide spectrum of bacterial diseases, from dental caries to pneumonia [122]. The new description defines biofilms as a microbial-derived sessile community of cells irreversibly attached to a substratum, interface or to each other, embedded in a matrix of extracellular polymeric substances (EPS) secreted by them and exhibit an altered phenotype of growth and gene transcription [119]. Biofilms are complex structures, highly resistant to environmental and therapeutic pressure. The primary polymeric compound of extracellular polymeric substance is alginate, a non-sulfated mucopolysaccharide described as a major biofilm component for multiple bacterial species, including those from the order Spirochaetales, Leptospira biflexa and Treponema denticola [123, 124] and Borrelia burgdorferi [96]. Even though the chemical structure of mature biofilms is diverse and includes phospholipids, polysaccharides, proteins, glycoproteins, embedded calcium and extracellular DNA (eDNA), alginine, calcium and eDNA are considered as a typical markers of biofilms [96]. The compilation of genes, conducted by $K$. Jefferson, that are required for biofilm formation (the cause genes) and 
those differentially expressed in an established biofilms (the effect genes) in multiple bacterial species include numerous genes involved in adhesion, quorum sensing, cell wall synthesis, metabolism, stress response division and motility [118]. Biofilms might be formed by a single bacteria species or represent a multi-species community attached to biotic or abiotic surfaces [121]. The physical characteristic of surfaces influence bacterial attachment only to a minor extent, showing that smooth surfaces are colonized with the same success as rough ones [125]. Once attached to the surface bacteria go through a series of changes that are required for adaptation to the life on surface. Extensive production of EPS is a common adaptation step; it protects the biofilms and might result in biocide resistance [126, 127]. The changes of environmental conditions triggers the transition of free-living bacteria to life on a surface that starts with the early stages that includes cell-surface and cell-cell interactions, followed by the development of mature biofilms and the return to a planktonic mode of growth. Those environmental signals vary and might differ among bacterial species, but in general what might influence the biofilms formation is the media composition/nutrition, temperature, $\mathrm{pH}$, osmolarity, iron or oxygen [121]. Surfaceattached bacteria are often associated with an increased synthesis of EPS and the development of antibiotic resistance, the feature that makes mature biofilms a serious clinical problem. It is known that EPS prevents the access of antibiotics to bacterial cells in the biofilm using different mechanisms that include physical or chemical diffusion barriers to antibiotic penetration, slow growth of the biofilms, activation of the stress response or appearance of a biofilm-specific phenotype [128].

The mode of biofilm formation of the causative agent of Lyme disease highly resembles that of other bacteria [129]. It has been shown that Borrelia is able to form colonies and develop aggregates with characteristic features of biofilms on biotic and abiotic substrates in a static or low-share-force environment. The use of the atomic force microscopy revealed the presence of channel-like structures in Borrelia biofilms that have been previously described in other biofilms and presumably serve as the routes of distribution of the oxygen and nutrition [119, 130]. Sapi et al. [96] showed that the protective extracellular substrate of Borrelia aggregates is predominantly composed of alginate with calcium and extracellular DNA. However, contrary to the other bacterial species that share the same pathway for alginine production, regulated by clustered $\operatorname{alg} A$, $\operatorname{alg} D$ and $\operatorname{algE}$ genes [131], Borrelia most probably uses a yet unknown pathway of alginate production as its genome lacks the genes homologous to that mentioned above. An analysis of the key components of Borrelia biofilm formation highlighted the impact of RpoN-RpoS alternative sigma factor pathways that are involved in the bacterial response to the environmental stresses and are responsible for sensing environmental stimuli [132]. The RpoN-RpoS signaltransduction pathway secures the successful transmission of the spirochete from tick to host, regulating the expression of over 100 genes involved in the infectious cycle, survival and stress response of Borrelia [133, 134]. Another regulatory pathway vital for Borrelia biofilm formation is the quorum sensing system, that by autoinducers triggers the population-wide differential regulation of genes involved in biofilm formation [135-137].

Borrelia biofilms have already been described in the midgut of infected tick nymphs during blood-feeding [5]. Using confocal and epifluorescence microscopy, the authors confirmed that during the blood-feeding Borrelia spirochetes progress through the nymphal midgut as epithelial cell-associated networks of non-motile organisms. Borrelia biofilms have also been detected in human infected skin [114]. The reoccurrence of the disease, the ability of spirochetes to evade the host immune system and the ability to resist antibiotic treatment strongly supports the existence of biofilm-like protective structures in infected patients.

\section{Conclusions}

The list of antibiotics recommended for LD treatment at the early stages of infection is expanding [12, 95, 96, 102, 108, 109, 114]. Current antibiotics are efficient in killing the growing replicative form of spirochetes, but they have rather insufficient activity against nongrowing persistent forms. It has been confirmed that monotherapy of Borrelia infection with $\beta$-lactam, tetracycline, fluoroquinolone, sulfonamide, macrolide, lipopeptide, glycopeptides, aminoglycoside or antitumor antibiotics are not adequate. Such treatment fails to eliminate spirochetes in in vitro culture and leaves viable and effective persisters in treated vertebrates, including humans $[12,17,18,49,85,106,108,109$, 117]. The obvious need in antibiotics with strong antipersister activity has led to the identification of drugs that act differently from current LD antibiotics [117]. However, even anti-persister drugs such as daptomycin, clofazimine or daunomycin cannot kill different persister forms such as cysts, round bodies, micro-colonies or biofilms alone. A combination of two or three drugs from different classes of antibiotics with different mechanisms of action along with the use of sulfa drugs shows significant improvement in eliminating multiple persisters' forms in vitro. Pulse dosing treatment shows great potential for eradicating persisters and seems to be a promising scheme for LD treatment. The interest in identifying alternative drug candidates with a high 
activity against multiple persister forms is growing. The other known "agent", comparable by its strength to triple-combination antibiotics treatment and efficient in eliminating $\log$ phase spirochetes as well as reducing persisters (by 94\%), is Stevia rebaudiana, the plant widely known as honey leaf or sweet leaf [138]. Most probably the killing power of this "agent", which is the whole leaf extract of the plant, is the result of the synergy of multiple natural compounds not yet identified. Recently, the screening of wide set of essential oils revealed candidates with an even stronger anti-persister activity than was described for some anti-persister drugs. For example, oregano oil and its active component carvacrol, cinnamon bark or clove bud were more efficient against the stationary phase and biofilms of Lyme disease spirochete than $40 \mu \mathrm{M}$ daptomycin. For comparison, $0.05 \%$ cinnamaldehyde, the active component of cinnamon bark essential oil, sterilized the LD spirochete at stationary phase and garlic essential oil was successful in killing of all forms of Borrelia at a concentration of $0.05 \%$. These results were confirmed by the absence of bacterial regrowth after 21 days of subculture and correspond to results obtained by culture treatment with $5 \mu \mathrm{g} / \mathrm{ml}$ of triple-drugs daptomycin + doxycycline + cefuroxime $[139,140]$. The majority of published results, dealing with promising or fairly successful anti-Borrelia drugs or their combinations, were obtained in vitro. There is no doubt that their effect on spirochetes in vivo will be different, may be unexpected, and definitely unpredictable. Evaluating the elimination capability of anti-Borrelia drugs or finding alternative candidates against multiple non-replicating forms of LD spirochetes should be taken to another level. Until the same experiments are conducted in vivo, involving multiple laboratory animal models, concerns about successful LD therapy protocol will remain at the discussion or speculation level. The success of LD therapy depends on how early antibiotic treatment is started. The question is how early is early enough to start antibiotic treatment in order to assure elimination of the replicating forms of spirochetes in an infected host, if a 7-10 day-old in vitro culture already contains multiple persistent forms of the pathogen [109]. If the signature marker of Lyme disease, erythema migrans, does not develop in a person after a tick bite, antibiotic treatment will not be initiated immediately. How much time might the motile form of bacteria need to change its morphology or to hide in vertebrate host tissues in vivo when such changes triggered by an unfriendly environment in vitro can occur in minutes or hours? Even if antibiotic monotherapy is started shortly after exposure to a tick, the LD treatment paradox could occur anyway: frontline LD antibiotics can trigger the establishment of a persister subpopulation in vivo as it has been proven by the confirmation of chronic infection in multiple animal species and humans [23, 48, $49,85,106,114]$. Atypical dormant spirochete forms, persisters, survive in a Borrelia-infected host for years, regardless of antibiotic treatment. The recurrence of LD likely happens because persisters may convert back into motile replicating infective forms under favorable growth conditions. The treatment of LD requires knowledge of its history and Borrelia pleomorphism in its natural environment [106]. The theory that chronic spirochete infections in humans are examples of symbioses that developed between the host and pathogen over time has been proposed for LD [106]. The humanBorrelia interaction represents co-evolved spirochetetick-host relationships highly integrated on genetic, metabolic and behavioral levels. From this point of view LD is a manifestation of long-lasting genetically integrated symbioses, and the disease symptoms are the expression of symbiogenesis to which many aspects of the host immune system respond [106]. Symbiogenesis means cooperation between species in order to increase their survival. While the benefit of symbiosis to the spirochete is obvious, what is the benefit of this symbiosis to the host? The successful persistence of spirochetes within the host is known to depend on their ability to use the host regulatory proteins to avoid recognition and eradication by its complement. Inability to understand chronic LD as ancient co-evolved host-pathogen symbioses might lead to misdiagnoses and insufficient therapies. The probability that chronic LD arises from a persisting infection is real. Regardless of the cause of chronic LD, i.e. persisting forms hidden in biofilms [49, 96], cell-wall deficient forms [31], or round bodies [15], the in vivo treatment options for all of them are very limited. Addressing this problem requires a new comprehensive examination of the complex and controversial subject called chronic Lyme disease.

\section{Abbreviations}

LD: Lyme diseases; RB: round bodies; EPS: extracellular polymeric substances; eDNA: extracellular DNA.

\section{Acknowledgements}

We are grateful to all research groups and the authors, cited in our paper, whose work encouraged this discussion. We are grateful to Marcia E. Herman-Giddens for her useful comments and help in manuscript language correction.

\section{Authors' contributions}

NR and MG developed the concept of the paper and wrote a draft version of the review. NR, MG, KK and MV contributed to the writing, editing and the revision of the manuscript. All authors read and approved the final manuscript. 


\section{Funding}

This study was supported by the Ministry of Education, Youth and Sport (LM2015062 Czech-Biolmaging and CZ.02.1.01/0.0/0.0/16_013/0001775) and Ministry of Health of the Czech Republic (NV19-05-00191).

\section{Availability of data and materials}

Not applicable.

\section{Ethics approval and consent to participate}

Not applicable.

\section{Consent for publication}

Not applicable.

\section{Competing interests}

The authors declare that they have no competing interests.

\section{Author details}

${ }^{1}$ Biology Centre CAS, Institute of Parasitology, Branisovska 31, 37005 Ceske Budejovice, Czech Republic. ${ }^{2}$ National Institute of Public Health, Srobarova 48, 10042 Prague 10, Czech Republic.

Received: 14 February 2019 Accepted: 9 May 2019

Published online: 16 May 2019

\section{References}

1. Singh SK, Girschick HJ. Molecular survival strategies of the Lyme disease spirochete Borrelia burgdorferi. Lancet Infect Dis. 2004;4:575-83.

2. Hovius J, van Dam AP, Fikrig E. Tick-host-pathogen interactions in Lyme borreliosis. Trends Parasitol. 2007;23:434-8.

3. Fikrif E, Narasimhan S. Borrelia burgdorferi-traveling incognito? Microb Infect. 2006;8:1390-9.

4. Kraiczy P. Hide and seek: how Lyme disease spirochetes overcome complement attack. Front Immunol. 2016;7:385.

5. Dunham-Ems SM, Caimano MJ, Pal U, Wolgemuth CW, Eggers $\mathrm{CH}$, Balic A, et al. Live imaging reveals a biphasic mode of dissemination of Borrelia burgdorferi within ticks. J Clin Investig. 2009;119:3652-65.

6. Samuels DS. Gene regulation in Borrelia burgdorferi. Annu Rev Microbiol. 2011;2011(65):479-99.

7. Drecktrah D, Lybecker M, Popitsch N, Rescheneder P, Hall LS, Samuels DS. The Borrelia burgdorferi ReIA/SpoT homolog and stringent response regulate survival in the tick vector and global gene expression during starvation. PLoS Pathog. 2015;11:e1005160.

8. Brorson $\mathrm{O}$, Brorson $\mathrm{SH}$. A rapid method for generating cystic forms of Borrelia burgdorferi and their reversal to mobile spirochetes. APMIS. 1998;106:1131-41.

9. Akins DR, Bourell KW, Caimano MJ, Norgard MV, Radolf JD. A new animal model for studying Lyme disease spirochetes in a mammalian host-adapted state. J Clin Investig. 1998;101:2240-50.

10. Carroll JA, Garon CF, Schwan TG. Effects of environmental pH on membrane proteins of Borrelia burgdorferi. Infect Immun. 1999:67:3181-7.

11. Hodzic E, Feng S, Freet KJ, Barthold SW. Borrelia burgdorferi population dynamics and prototype gene expression during infection of immunocompetent and immunodeficient mice. Infect Immun. 2003;71:5042-55.

12. Feng J, Shi W, Zhang S, Zhang YP. Persister mechanisms in Borrelia burgdorferi: implications for improved intervention. EMI. 2015:4:e51.

13. Wu Q, Guan G, Liu Z, Li Y, Luo J, Yin H. RNA-Seq-based analysis of changes in Borrelia burgdorferi gene expression linked to pathogenicity. Parasites Vectors. 2015:8:155.

14. Alban PS, Johnson PW, Nelson DR. Serum-starvation-induced changes in protein synthesis and morphology of Borrelia burgdorferi. Microbiology. 2000;146:119-27

15. Gruntar I, Malovrh T, Murgia R, Cinco M. Conversion of Borrelia garinil cystic forms to motile spirochetes in vivo. APMIS. 2001;109:383-8.

16. Lewis K. Persister cells. Annu Rev Microbiol. 2010;64:357-72.

17. Hodzic E, Imai D, Feng S, Barthold SW. Resurgence of persisting noncultivable Borrelia burgdorferi following antibiotic treatment in mice. PLOS ONE. 2014;9:e86907.
18. Sharma B, Brown AV, Matluck NE, Hu LT, Lewis K. Borrelia burgdorferi, the causative agent of Lyme disease, forms drug-tolerant persister cells. Antimicrob Agents Chemother. 2015;59:4616-24

19. Cabello FC, Godfrey HP, Newman SA. Hidden in plain sight: Borrelia burgdorferi and the extracellular matrix. Trends Microbiol. 2007;15:350-4.

20. Tilly K, Rosa PA, Stewart PE. Biology of infection with Borrelia burgdorferi. Infect Dis Clin N Am. 2007;22:217-34.

21. Liang FT, Brown EL, Wang T, lozzo RV, Fikrig E. Protective niche for Borrelia burgdorferi to evade humoral immunity. Am J Pathol. 2004;165:977-85.

22. Yrjänäinen $\mathrm{H}$, Hytonen J, Soderstrom KO, Oksi J, Hartiala K, Viljanen MK. Persistent joint swelling and Borrelia-specific antibodies in Borrelia garinii-infected mice after eradication of vegetative spirochetes with antibiotic treatment. Microbes Infect. 2006;8:2044-51.

23. Hodzic E, Feng S, Holden K, Freet KJ, Barthold SW. Persistence of Borrelia burgdorferi following antibiotic treatment in mice. Antimicrob Agents Chemother. 2008;52:1728-36.

24. Barthold SW, deSouza MS, Janotka JL, Smith AL, Persing DH. Chronic Lyme borreliosis in the laboratory mouse. Am J Pathol. 1993;143:951-71.

25. Barthold SW, Hodzic E, Imai DM, Feng S, Yang X, Luft BJ. Ineffectiveness of tigecycline against persistent Borrelia burgdorferi. Antimicrob Agents Chemother. 2010;54:643-51.

26. Bockenstedt LK, Gonzalez DG, Haberman AM, Belperron AA. Spirochete antigens persist near cartilage after murine Lyme borreliosis therapy. J Clin Investig. 2012:122:2652-60.

27. Yrjänäinen H, Hytönen J, Song XR, Oksi J, Hartiala K, Viljanen MK. Antitumor necrosis factor-a treatment activates Borrelia burgdorferi spirochetes 4 weeks after ceftriaxone treatment in C3H/He mice. J Infect Dis. 2007:195:1489-96.

28. Yrjänäinen H, Hytönen J, Hartiala P, Oksi J, Viljanen MK. Borrelia burgdorferi DNA in joints and tissue adjacent to the joint is the niche of persisting burgdorferi in ceftriaxone-treated mice. APMIS. 2010;118:665-73.

29. Baum E, Hue F, Barbour AG. Experimental infections of the reservoir species Peromyscus leucopus with diverse strains of Borrelia burgdorferi, a Lyme disease agent. MBio. 2012;3:e00434-12.

30. Schwan TG, Burgdorfer W, Schrumpf ME, Karstens RH. The urinary bladder: a consistent source of Borrelia burgdorferi in experimentally infected white-footed mice (Peromyscus leucopus). J Clin Microbiol. 1988;26:893-5.

31. Moody KD, Barthold SW, Terwilliger GA, Beck DS, Hansen GM, Jacoby RO. Experimental chronic Lyme borreliosis in Lewis rats. Am J Trop Med Hyg. 1990;42:65-74

32. Duray PH, Johnson RC. The histopathology of experimentally infected hamsters with the Lyme disease spirochete, Borrelia burgdorferi. Proc Soc Exp Biol Med. 1986;181:263-9.

33. Goodman JL, Jurkovich P, Kodner C, Johnson RC. Persistent cardiac and urinary tract infections with Borrelia burgdorferi in experimentally infected Syrian hamsters. J Clin Microbiol. 1991;29:894-6.

34. Sonnesyn SW, Manivel JC, Johnson RC, Goodman JL. A guinea pig model for Lyme disease. Infect Immun. 1993;61:4777-8.

35. Schmitz IL Schell RF, Lovrich SD, Callister SM, Coe JE Characterization of the protective antibody response to Borrelia burgdorferi in experimentally infected LSH hamsters. Infect Immun. 1991;59:1916-21.

36. Preac-Mursic V, Patsouris E, Wilske B, Reinhardt S, Gos B, Mehraein P. Persistence of Borrelia burgdorferi and histopathological alterations in experimentally infected animals; comparison with histopathological findings in human Lyme disease. Infection. 1990;18:332-41.

37. Straubinger RK, Summers BA, Chang YF, Appel MJ. Persistence of Borrelia burgdorferi in experimentally infected dogs after antibiotic treatment. J Clin Microbiol. 1997:35:111-6.

38. Straubinger RK, Straubinger AF, Summers BA, Jacobson RH. Status of Borrelia burgdorferi infection after antibiotic treatment and the effects of corticosteroids: an experimental study. J Infect Dis. 2000;181:1069-81.

39. Straubinger RK, Straubinger AF, Jacobson RH, Chang Y, Summers BA, Erb HN, et al. Two lessons from the canine model of Lyme disease: migration of Borrelia burgdorferi in tissues and persistence after antibiotic treatment. J Spirochetal Tick Borne Dis. 1997;4:24-31. 
40. Chang YF, Ku YW, Chang CF, Chang CD, McDonough SP, Divers T, et al. Antibiotic treatment of experimentally Borrelia burgdorferi-infected ponies. Vet Microbiol. 2005;107:285-94.

41. Imai DM, Barr BC, Daft B, Bertone JJ, Feng S, Hodzic E, et al. Lyme neuroborreliosis in 2 horses. Vet Pathol. 2011:48:1151-7.

42. James FM, Engiles JB, Beech J. Meningitis, cranial neuritis, and radiculoneuritis associated with Borrelia burgdorferi infection in a horse. J Am Vet Med A. 2010;10:1180-5.

43. Embers ME, Hasenkampf NR, Jacobs MB, Tardo AC, Doyle-Meyers LA, Philipp MT, et al. Variable manifestations, diverse seroreactivity and post-treatment persistence in non-human primates exposed to Borrelia burgdorferi by tick feeding. PLoS ONE. 2017;12:e0189071.

44. Roberts ED, Bohm RP Jr, Cogswell FB, Lanners HN, Lowrie RC Jr, et al. Chronic Lyme disease in the rhesus monkey. Lab Investig. 1995;72:146-60.

45. Roberts ED, Bohm RP Jr, Lowrie RC Jr, Habicht G, Katona L, Piesman J, et al. Pathogenesis of Lyme neuroborreliosis in the rhesus monkey: the early disseminated and chronic phases of disease in the peripheral nervous system. J Infect Dis. 1998;178:722-32.

46. Cadavid D, Bai Y, Hodzic E, Narayan K, Barthold SW, Pachner AR. Cardiac involvement in non-human primates infected with the Lyme disease spirochete Borrelia burgdorferi. Lab Investig. 2004;84:1439-50.

47. Hefty PS, Brooks CS, Jett AM, White GL, Wikel SK, Kennedy RC, et al. OspE-related, OspF-related, and Elp lipoproteins are immunogenic in baboons experimentally infected with Borrelia burgdorferi and in human Lyme disease patients. J Clin Microbiol. 2002;40:4256-65.

48. Stricker RB, Johnson L. Persistent infection in chronic Lyme disease: does form matter? Res J Infect Dis. 2013;1:2.

49. Embers ME, Barthold SW, Borda JT, Bowers L, Doyle L, Hodzic E, et al. Persistence of Borrelia burgdorferi in rhesus macaques following antibiotic treatment of disseminated infection. PLoS ONE. 2012;7:e29914

50. Steere AC, Malawista SE, Hardin JA, Ruddy S, Askenase PW, Andiman WA. Erythema chronicum migrans and Lyme arthritis: the enlarging clinical spectrum. Ann Intern Med. 1977;86:685-98.

51. Middelveen MJ, Sapi E, Burke J, Filush KR, Franco A, Fesler MC, et al. Persistent borrelia infection in patients with ongoing symptoms of Lyme disease. Healthcare. 2018;6:33.

52. Berger BW. Treating erythema chronicum migrans of Lyme disease. J Am Acad Dermatol. 1986;3:459-63.

53. Liegner KB, Shapiro JR, Ramsay D, Halperin AJ, Hogrefe W, Kong L. Recurrent erythema migrans despite extended antibiotic treatment with minocycline in a patient with persisting Borrelia burgdorferi. J Am Acad Dermatol. 1993;28:312-4.

54. Schmidli J, Hunziker T, Moesli P, Schaad UB. Cultivation of Borrelia burgdorferi from joint fluid three months after treatment of facial palsy due to Lyme borreliosis. J Inf Dis. 1988;158:905-6.

55. Dattwyler RJ, Volkman DJ, Luft BJ, Halperin JJ, Thomas J, Golightly MG. Seronegative Lyme disease. Dissociation of specific T- and B-lymphocyte response to Borrelia burgdorferi. N Engl J Med. 1988;319:1441-6.

56. Weber K, Bratzke HJ, Neubert U, Wilske B, Duray PH. Borrelia burgdorferi in a newborn despite oral penicillin for Lyme borreliosis during pregnancy. Pediatr Infect Dis J. 1988;7:286-9.

57. Steere AC, Duray PH, Butcher EC. Spirochetal antigens and lymphoid cell surface markers in Lyme synovitis. Comparison with rheumatoid synovium and tonsillar lymphoid tissue. Arthritis Rheum. 1988;31:487-95.

58. Preac-Mursic V, Weber K, Pfister HW, Wilske B, Gross B, Baumann A, et al. Survival of Borrelia burgdorferi in antibiotically treated patients with Lyme borreliosis. Infection. 1989;17:355-9.

59. Girschick HJ, Huppertz HI, Rüssmann H, Krenn V, Karch H. Intracellular persistence of Borrelia burgdorferi in human synovial cells. Rheumatol Int. 1996;16:125-32.

60. Cimmino MA, Azzolini A, Tobia F, Pesce CM. Spirochetes in the spleen of a patient with chronic Lyme disease. Am J Clin Pathol. 1989;91:95-7.

61. Pfister HW, Preac-Mursic V, Wilske B, Schielke E, Sorgel F, Einhaupl KMJ. Randomized comparison of ceftriaxone and cefotaxime in Lyme neuroborreliosis. Infect Dis. 1991;163:311-8.

62. Logigian EL, Kaplan RF, Steere AC. Chronic neurologic manifestations of Lyme disease. N Engl J Med. 1990;323:1438-44.

63. Battafarano DF, Combs JA, Enzenauer RJ, Fitzpatrick JE. Chronic septic arthritis caused by Borrelia burgdorferi. Clin Orthop. 1993;297:238-41.
64. Häupl T, Hahn G, Rittig M, Krause A, Schoerner C, Schonherr U, et al. Persistence of Borrelia burgdorferi in ligamentous tissue from a patient with chronic Lyme borreliosis. Arthritis Rheum. 1993;36:1621-6.

65. Strle F, Preac-Mursic V, Cimperman J, Ruzic E, Maraspin V, Jereb M. Azithromycin versus doxycycline for treatment of erythema migrans: clinical and microbiological findings. Infection. 1993;21:83-8.

66. Preac-Mursic V, Pfister HW, Spiegel H, Burk R, Wilske B, Reinhardt S, et al. First isolation of Borrelia burgdorferi from an iris biopsy. J Clin Neuroophthalmol. 1993;13:155-61.

67. Strle F, Maraspin V, Lotric-Furlan S, Ruziç-Sabljiç E, Cimperman J. Azithromycin and doxycycline for treatment of Borrelia culture-positive erythema migrans. Infection. 1996;24:64-8.

68. Preac-Mursic V, Marget W, Busch U, Pleterski Rigler D, Hagl S. Kill kinetics of Borrelia burgdorferi and bacterial findings in relation to the treatment of Lyme borreliosis. Infection. 1996;24:9-16.

69. Shadick NA, Phillips CB, Logigian EL, Steere AC, Kaplan RF, Berardi VP, et al. The long-term clinical outcomes of Lyme disease. A populationbased retrospective cohort study. Ann Int Med. 1994;121:560-7.

70. Oksi J, Kalimo H, Marttila RJ, Marjamäki M, Sonninen P, Nikoskelainen $J$, et al. Inflammatory brain changes in Lyme borreliosis. A report on three patients and review of literature. Brain. 1996;119:2143-54.

71. Priem S, Burmester GR, Kamradt T, Wolbart K, Rittig MG, Krause A. Detection of Borrelia burgdorferi by polymerase chain reaction in synovial membrane, but not in synovial fluid from patients with persisting Lyme arthritis after antibiotic therapy. Ann Rheum Dis. 1998;57:118-21.

72. Oksi J, Marjamaki M, Nikoskelainen J, Viljanen MK. Borrelia burgdorferi detected by culture and PCR in clinical relapse of disseminated Lyme borreliosis. Ann Med. 1999;31:225-32.

73. Weber K. Treatment failure in erythema migrans: a review. Infection. 1996:24:73-5.

74. Honegr K, Hulínská D, Beran J, Dostál V, Havlasová J, Čermáková Z. Long term and repeated electron microscopy and PCR detection of Borrelia burgdorferi sensu lato after an antibiotic treatment. Cent Eur J Public Health. 2004:12:6-11.

75. Breier F, Khanakah G, Stanek G, Kunz G, Aberer E, Schmidt B, et al. Isolation and polymerase chain reaction typing of Borrelia afzelii from a skin lesion in a seronegative patient with generalized ulcerating bullous lichen sclerosus et atrophicus. Br J Dermatol. 2001;144:387-92.

76. Hunfeld KP, Ruzic-Sabljic E, Norris DE, Kraiczy P, Strle F. In vitro susceptibility testing of Borrelia burgdorferi sensu lato isolates cultured from patients with erythema migrans before and after antimicrobial chemotherapy. Antimicrob Agents Chemother. 2005;49:1294-301.

77. Hudson BJ, Stewart M, Lennox VA, Fukunaga M, Yabuki M, Macorison H, et al. Culture-positive Lyme borreliosis. Med J Aust. 1998;168:500-2.

78. Kirsch M, Ruben FL, Steere AC, Duray PH, Norden CW, Winkelstein A. Fatal adult respiratory distress syndrome in a patient with Lyme disease. J Am Med Assoc. 1988;259:2737-9.

79. Chancellor MB, McGinnis DE, Shenot PJ, Kiilholma P, Hirsch $\Vdash H$. Urinary dysfunction in Lyme disease. J Urol. 1993;149:26-30.

80. Nocton JJ, Dressler F, Rutledge BJ, Rys PN, Persing DH, Steere AC. Detection of Borrelia burgdorferi DNA by polymerase chain reaction in synovial fluid from patients with Lyme arthritis. N Engl J Med. 1994;330:229-34.

81. Masters E. Spirochetemia after continuous high-dose oral amoxicillin therapy. Infect Dis Clin Pract. 1994;3:207-8.

82. Lawrence C, Lipton RB, Lowy FD, Coyle PK. Seronegative chronic relapsing neuroborreliosis. Eur Neurol. 1995;35:113-7.

83. Bayer ME, Zhang L, Bayer MH. Borrelia burgdorferi DNA in the urine of treated patients with chronic Lyme disease symptoms. A PCR study of 97 cases. Infection. 1996:24:347-53.

84. Nocton JJ, Bloom BJ, Rutledge BJ. Detection of Borrelia burgdorferi DNA by polymerase chain reaction in cerebrospinal fluid in Lyme neuroborreliosis. J Infect Dis. 1996;174:623-7.

85. Rudenko N, Golovchenko M, Vancova M, Clark K, Grubhoffer L, Oliver $\mathrm{JH} \mathrm{J}$. Isolation of live Borrelia burgdorferi sensu lato spirochetes from patients with undefined disorders and symptoms not typical for Lyme diseases. Clin Microbiol Infect. 2016;22:267.e9-15. 
86. Shapiro ED. Repeat or persistent Lyme disease: persistence, recrudescence or reinfection with Borrelia burgdorferi? F1000Prime Rep. 2015;7:11.

87. Embers ME, Ramamoorthy R, Philipp MT. Survival strategies of Borrelia burgdorferi, the etiologic agent of Lyme disease. Microb Infect. 2004;6:312-8.

88. Steere AC. Lyme disease. N Engl J Med. 2001;345:115-25.

89. Wormser GP, Dattwyler RJ, Shapiro ED, Halperin JJ, Steere AC, Klempner MS, et al. The clinical assessment, treatment, and prevention of Lyme disease, human granulocytic anaplasmosis, and babesiosis: clinical practice guidelines by the Infectious Diseases Society of America. Clin Infect Dis. 2006:43:1089-134.

90. Hu LT. In the clinic. Lyme disease. Ann Intern Med. 2012;157:ITC2-2--16.

91. Hobby GL, Meyer K, Chaffee E. Observations on the mechanism of action of penicillin. Exp Biol Med. 1942;50:281-5.

92. Bigger JW. Treatment of staphylococcal infections with penicillin by intermittent sterilization. Lancet. 1944:244:497-500.

93. Keren I, Kaldalu N, Spoering A, Wang Y, Lewis K. Persister cells and tolerance to antimicrobials. FEMS Microbiol Lett. 2004;230:13-8

\section{(Erratum in: FEMS Microbiol Lett. 34,187).}

94. Fauvart M, De Groote VN, Michiels J. Role of persister cells in chronic infections: clinical relevance and perspectives on anti-persister therapies. J Med Microbiol. 2011;60:699-709.

95. Zhang Y. Persisters, persistent infections and the Yin-Yang model. Emerg Microbes Infect. 2014;3:e3.

96. Sapi E, Bastian SL, Mpoy CM, Scott S, Rattelle A, Pabbati N, et al. Characterization of biofilm formation by Borrelia burgdorferi in vitro. PLoS ONE. 2012;7:e48277.

97. Kurtti TJ, Munderloh UG, Johnson RC, Ahlstrand GG. Colony formation and morphology in Borrelia burgdorferi. J Clin Microbiol. 1987;25:2054-8.

98. Aberer E, Kersten A, Klade H, Poitschek C, Jurecka W. Heterogeneity of Borrelia burgdorferi in the skin. Am J Dermatopathol. 1996;18:571-9.

99. Mursic VP, Wanner G, Reinhardt S, Wilske B, Busch U, Marget W. Formation and cultivation of Borrelia burgdorferi spheroplast-L-form variants. Infection. 1996;24:218-26.

100. Brorson O, Brorson SH. Transformation of cystic forms of Borrelia burgdorferi to normal, mobile spirochetes. Infection. 1997;25:240-6.

101. Miklossy J, Kasas S, Zurn AD, McCall S, Yu S, McGeer PL. Persisting atypical and cystic forms of Borrelia burgdorferi and local inflammation in Lyme borreliosis. J Neuroinflamm. 2008:5:40.

102. Sapi E, Kaur N, Anyanwu S, Luecke DF, Datar A, Patel S, et al. Evaluation of in-vitro antibiotic susceptibility of different morphological forms of Borrelia burgdorferi. Infect Drug Resist. 2011;4:97-113.

103. Meriläinen L, Herranen A, Schwarzbach A, Gilbert L. Morphological and biochemical features of Borrelia burgdorferi pleomorphic form. Microbiology. 2015;161:516-27.

104. Murgia R, Cinco M. Induction of cystic forms by different stress conditions in Borrelia burgdorferi. APMIS. 2004;112:57-62.

105. Kersten A, Poitschek C, Rauch S, Aberer E. Effects of penicillin, ceftriaxone, and doxycycline on morphology of Borrelia burgdorferi. Antimicrob Agents Chemother. 1995;39:1127-33.

106. Brorson O, Brorson SH, Scythes J, MacAllister J, Wier A, Margulis L. Destruction of spirochete Borrelia burgdorferi round-body propagules (RBs) by the antibiotic tigecycline. Proc Natl Acad Sci USA. 2009;106:18656-61.

107. Caskey JR, Embers ME. Persister development by Borrelia burgdorferi populations in vitro. Antimicrob Agents Chemother. 2015;59:6288-95.

108. Feng J, Wang T, Shi W, Zhang S, Sullivan D, Auwaerter PG, et al. Identification of novel activity against Borrelia burgdorferi persisters using an FDA approved drug library. EMI. 2014;3:e49.

109. Feng J, Shi W, Zhang S, Sullivan D, Auwaerter PG, Zhang Y. A drug combination screen identifies drugs active against amoxicillininduced round bodies of in vitro Borrelia burgdorferi persisters from an FDA drug library. Front Microbiol. 2016;7:743.

110. Dubinina G, Grabovich M, Leshcheva N, Rainey FA, Gavrish E. Spirochaeta perfilievii sp. nov., a novel oxygen-tolerant, sulfide oxidizing, sulfur and thiosulfate reducing spirochete isolated from a saline spring. Int J Syst Evol Microbiol. 2011;61:110-7.

111. Droge S, Frohlich J, Radek R, Konig H. Spirochaeta coccoides sp. nov., a novel coccoid spirochete from the hindgut of the termite Neotermes castaneus. Appl Environ Microbiol. 2006;72:391-7.

112. Dutton JE, Todd JL. The nature of human tick fever in the eastern part of the Congo Free State. Liverpool Sch Trop Med Hyg. 1905:17:1-18.

113. Hoogenraad NJ, Hird FJR, Holmes I, Millis NF. Bacteriophages in rumen contents of sheep. J Gen Virol. 1967;1:575-6.

114. Sapi E, Balasubramanian K, Poruri A, Maghsoudlou JS, Theophilus PAS, Socarras KM, et al. Evidence of in vivo existence of Borrelia biofilm in borrelial lymphocytomas. Eur J Microbiol Immunol. 2016;6:9-24.

115. Eisendle K, Zelger B. The expanding spectrum of cutaneous borreliosis. G Ital Dermatol Venereol. 2009;144:157-71.

116. Olivares J, Bernardini A, Garcia-Leon G, Corona FB, Sanchez M, Martinez JL. The intrinsic resistome of bacterial pathogens. Front Microbiol. 2013;4:103

117. Feng J, Auwaerter PG, Zhang Y. Drug combinations against Borrelia burgdorferi persisters in vitro: eradication achieved by using daptomycin, cefoperazone and doxycycline. PLOS ONE. 2015;10:e0117207.

118. Jefferson KK. What drives bacteria to produce biofilm? FEMS Microbiol Lett. 2004;236:163-73.

119. Donlan RM, Costerton JW. Biofilms: survival mechanisms of clinically relevant microorganisms. Clin Microbiol Rev. 2002;15:167-93.

120. Lewis K. Riddle of biofilm resistance. Antimicrob Agents Chemother. 2001;45:999-1007.

121. O'Toole G, Kaplan HB, Kolter R. Biofilm formation as microbial development. Annu Rev Microbiol. 2000;54:49-79.

122. Costerton JW, Geesey GG, Cheng KJ. How bacteria stick. Sci Am. 1978;238:86-95.

123. Vesey PM, Kuramitsu HK. Genetic analysis of Treponema denticola ATCC 35405 biofilm formation. Microbiol. 2004;150:2401-7.

124. Ristow P, Bourhy P, Kerneis S, Schmitt C, Prevost M-C, Lilenbaum W, et al. Biofilm formation by saprophytic and pathogenic leptospires. Microbiol. 2008:154:1309-17.

125. Costerton JW, Lewandowski Z, Caldwell DE, Korber DR, Lappin-Scott HM. Microbial biofilms. Annu Rev Microbiol. 1995;49:711-45.

126. Bayer AS, Speert DP, Park S, Tu J, Witt M, Nast CC, et al. Functional role of mucoid exopolysaccharide (alginate) in antibiotic-induced and polymorphonuclear leukocyte-mediated killing of Pseudomonas aeruginosa. Infect Immun. 1991;59:302-8.

127. Gacesa P. Bacterial alginate biosynthesis: recent progress and future prospects. Microbiology. 1998;144:1133-43.

128. Mah T-FC, O'Toole GA. Mechanisms of biofilm resistance to antimicrobial agents. Trends Microbiol. 2001;1:34-9.

129. Costerton JW, Stewart PS, Greenburg EP. Bacterial biofilms, a common cause of persistent infections. Science. 1999:284:1318-22.

130. Branda SS, Vik S, Friedman L, Kolter R. Biofilms: the matrix revisited. Trends Microbiol. 2005;13:20-6.

131. Remminghorst $U$, Rehm BHA. Bacterial alginates: from biosynthesis to applications. Biotechnol Lett. 2006;28:1701-12.

132. Kazmierczak MJ, Wiedmann M, Boor KJ. Alternative sigma factors and their roles in bacterial virulence. Microbiol Mol Biol Rev. 2005;69:527-43.

133. Ouyang Z, Narasimhan S, Neelakanta G, Kumar M, Pal U, Fikrig E, et al. Activation of the RpoN-RpoS regulatory pathway during the enzootic life cycle of Borrelia burgdorferi. BMC Microbiol. 2012;12:44.

134. Dunham-Ems SM, Caimano MJ, Eggers CH, Radolf JD. Borrelia burgdorferi requires the alternative sigma factor RpoS for dissemination within the vector during tick-to mammal transmission. PLoS Pathog. 2012;8:e1002532

135. Waters CM, Bassler BL. Quorum sensing: cell-to-cell communication in bacteria. Annu Rev Cell Dev Biol. 2005;21:319-46.

136. Bassler BL. How bacteria talk to each other: regulation of gene expression by quorum sensing. Curr Opin Microbiol. 1999;2:582-7.

137. Schauder S, Shokat K, Surette MG, Bassler BL. The LuxS family of bacterial autoinducers: biosynthesis of a novel quorum-sensing signal molecule. Mol Microbiol. 2001;41:463-76. 
138. Theophilus PA, Victoria MJ, Socarras KM, Filush KR, Gupta K, Luecke DF, et al. Effectiveness of Stevia rebaudiana whole leaf extract against the various morphological forms of Borrelia burgdorferi in vitro. Eur J Microbiol Immunol. 2015;5:268-80.

139. Feng J, Zhang S, Shi W, Zubcevik N, Miklossy J, Zhang Y. Selective essential oils from spice or culinary herbs have high activity against stationary phase and biofilm Borrelia burgdorferi. Front Med. 2017:4:169.

140. Feng J, Shi W, Miklossy J, Tauxe GM, McMeniman CJ, Zhang Y. Identification of essential oils with strong activity against stationary phase Borrelia burgdorferi. Antibiotics. 2018;7:89.

\section{Publisher's Note}

Springer Nature remains neutral with regard to jurisdictional claims in published maps and institutional affiliations.
Ready to submit your research? Choose BMC and benefit from:

- fast, convenient online submission

- thorough peer review by experienced researchers in your field

- rapid publication on acceptance

- support for research data, including large and complex data types

- gold Open Access which fosters wider collaboration and increased citations

- maximum visibility for your research: over $100 \mathrm{M}$ website views per year

At BMC, research is always in progress.

Learn more biomedcentral.com/submissions 